\title{
A Construção e Desenvolvimento do Turismo no Espaço Rural em Portugal: o papel da administração central nos seus conteúdos
}

\section{The Construction and Development of Tourism in Rural Space: the role of the central administration in its contents}

\section{La Construcción y el Desarrollo del Turismo Rural en Portugal: el papel del gobierno central en su contenidos}

Lúcia Pato ${ }^{1}$

\begin{abstract}
Resumo
Desde cedo que a administração central do estado tem tido uma influência notável na difusão do setor do turismo rural em Portugal, contando o produto oficialmente designado como "turismo no espaço rural" (TER) com aproximadamente três décadas. Não obstante algumas experiências anteriores, o TER foi criado em 1986 contando nesse ano com apenas três modalidades de alojamento. $\mathrm{O}$ espaço rural foi assim consagrado como um espaço de turismo, um turismo que sendo novo se materializava como um produto sustentável e familiar e por essa via distinto dos que preenchiam o mercado. As exigências em termos de construção, mobiliário e decoração, dificultavam no entanto o acesso à larga maioria das populações rurais e aos pequenos e médios agricultores. Decorreram mais de dez anos até às questões de desenvolvimento rural serem assumidas como um dos objetivos a atribuir ao TER. Na legislação de 1997 o conceito é redefinido, o TER é alargado a duas novas modalidades de alojamento mais populares e ao domínio da animação turística. Apesar da ênfase na valorização do património das zonas rurais, em 2002, com a nova redefinição da legislação, as questões relativas ao desenvolvimento rural parecem ter sido esquecidas pela administração central. Data de 2008 a última grande alteração em termos da conceção do produto turístico. O TER perde aqui a modalidade que esteve na sua conceção (turismo de habitação), não sendo igualmente referidas as questões relativas ao desenvolvimento rural e à familiaridade dos empreendimentos afetos à atividade.
\end{abstract}

Palavras-Chave: Turismo Rural; Legislação; Portugal.

\begin{abstract}
Since early on, that the central administration of the state has had a remarkable influence on the spread of rural tourism in Portugal, with nearly of three decades of the officially labelled as Turismo no Espaço Rural (TER). Despite some previous experiences, TER was created in 1986 integrating only three types of lodging units. The rural space was officially elected a space of tourism, a tourism that was new and emerged as a sustainable and familiar product and for that reason was different from the existing one in the market. The requirements in
\end{abstract}

\footnotetext{
${ }^{1}$ Doutorada em Turismo pela Universidade de Aveiro. Professora Adjunta no Instituto Politécnico de Viseu (IPV) - Escola Superior Agrária. Investigadora na Unidade de Investigação CI\&DETS do IPV. Aveiro, Portugal. Email: mljesus@sapo.pt
} 
terms of construction, furniture and decoration, made it difficult the access of a large majority of rural population as well as small and medium farmers. More than ten years have passed since the issues of rural development have been assumed as one of the goals of TER. In the legislation of 1997 the concept of TER was redefined and was extended to two new popular lodging units as well as recreational activities. Despite the emphasis on the value of the heritage of rural areas in 2002 with the new redefinition of TER legislation, the issues related with rural development seem to be forgotten by the central administration. The last major change in terms of the conception of the tourism product was in 2008. Here TER loses its first type of lodging unit (tourism in a manor-house). Additionally the issues of rural development, once again, seem to be forgotten and TER seems to lose its familiarity.

Keywords: Rural Tourism; Legislation; Portugal

\section{Resumen}

Desde el principio de que la administración central del Estado ha tenido una notable influencia en la propagación del sector del turismo rural en Portugal, contando el producto designado oficialmente como "turismo rural" (TER) con casi tres décadas. A pesar de cierta experiencia previa, el TER fue creado en 1986 a contar este año con sólo tres tipos de alojamiento. El campo estaba bien establecida como una zona turística, una gira que ser nuevo se materializó como un producto sostenible y familiar y de esa forma distinta de los que llenó el mercado. Los requisitos en materia de construcción, muebles y decoración, sin embargo obstaculizan el acceso a una gran mayoría de las poblaciones rurales y los pequeños y medianos agricultores. Se llevó a cabo más de diez años para los temas de desarrollo rural se supone que son una de las metas para dar el TER. La ley de 1997, el concepto se redefine, el TER se extiende a dos nuevos arreglos de alojamiento populares y el área de las actividades turísticas. A pesar del énfasis en la valorización del patrimonio de las zonas rurales en 2002 con la nueva redefinición de la ley, cuestiones de desarrollo relacionadas rurales parecen olvidados por el gobierno central. De 2008, el último gran cambio en cuanto al diseño del producto turístico. El TER aquí pierde modalidad que estaba en su concepción (alojamientos de alquiler) y no se refirió también a cuestiones relacionadas con el desarrollo rural y la familiaridad de los acontecimientos afecto a la actividad.

Palabras-clave: Turismo Rural, Ley, Portugal

\section{Introdução}

Em Portugal o desenvolvimento do turismo começou a desenhar-se a partir de finais dos anos cinquenta, com base em produtos muitos específicos, dos quais se salienta por ordem decrescente de importância: o sol e praia, as cidades e monumentos e os centros religiosos (RIBEIRO, 2003). De acordo com a autora citada, o litoral, em especial o litoral algarvio, a costa e a cidade de Lisboa e o centro religioso de Fátima constituíam-se nesta altura como os grandes centros de atração turística. E turismo era (quase) exclusivo do litoral. A atividade 
transformou-se gradualmente numa atividade económica, mal conhecida do país, quer quanto aos seus efeitos quer quanto ao seu enquadramento, mas extremamente atraente e, aparentemente fácil (CUNHA, 2006). Multiplicaram-se, por esta via, os empreendimentos turísticos desligados de uma conceção de desenvolvimento regional e sem infraestruturas adequadas, donde resultaram os primeiros desgastes e problemas a nível do ambiente e do património cultural.

Apesar do extraordinário crescimento da procura nos anos seguintes, o turismo português passou a viver em estado de crise derivada não só do excesso da oferta e da pressão das infraestruturas em determinados locais, mas também do excesso da procura marcado por correntes massificadas de turistas.

O fomento de destinos alternativos aos convencionais e exclusivos do litoral, prefigurou-se neste contexto, como uma medida a adotar, tanto mais que se tornavam cada vez mais evidentes os problemas das áreas rurais do interior do país. Por seu turno, começava a surgir gradualmente um novo tipo de turistas, que procurava novas experiências, também elas mais sustentáveis, humanas e integradas nos locais de destino (URRY, 2002).

No âmbito destas procuras, da necessidade de diversificar o turismo nacional e da generalizada convicção que o turismo pode dar à superação dos graves problemas socioeconómicos que caracterizam as áreas do interior do país, em especial as mais desfavorecidas, o turismo em áreas rurais tem sido crescentemente enfatizado. Este pode constituir-se como um meio privilegiado de promoção dos recursos existentes nesses territórios rurais, um fator de revitalização do tecido económico e social e como tal, uma oportunidade para o desenvolvimento desses territórios (IESE, 2008). E hoje em dia, é aliás considerado um dos setores de atividade económica mais interessantes e promissores em algumas áreas rurais, para além de se ter tornado parte integrante dos planos de desenvolvimento rural e das políticas nacionais. Acresce ainda que, a atividade tem vindo a ser apoiada pelas políticas de desenvolvimento territorial e rural, nomeadamente pelas medidas enquadradas nos programas de iniciativa comunitária LEADER e por outras iniciativas de desenvolvimento rural.

A administração central na figura da então Direção Geral do Turismo e posteriormente do Turismo de Portugal não foram e (são) alheios às potencialidades do turismo rural, tendo desde cedo definido políticas de incremento de um novo produto turístico em áreas rurais - o 
turismo em espaço rural (TER). No entanto, quase sempre o grande propósito destas políticas centrou-se no desenvolvimento do turismo em desfavor (pelo menos parcial) do desenvolvimento das áreas rurais. Certo é também que, em virtude das exigências em termos de construção, mobiliário e demais requisitos que a legislação impunha aos eventuais promotores do produto turístico, não poderiam beneficiar com tais políticas a larga maioria dos habitantes das áreas rurais e os micro e pequenos agricultores.

No sentido de elucidar o propósito principal destas políticas, neste texto, centrar-me-ei na observação da conceção e desenvolvimento da oferta do turismo rural em Portugal, mais especificamente na influência indubitável da administração central nesse processo. Para tal, para além da revisão da literatura respeitante ao turismo rural, especificamente das suas características e propósitos, foram objeto de revisão os decretos leis e portarias que estiveram na origem e no desenvolvimento do TER em Portugal. A análise e tratamento da informação constante destes decretos-leis e portarias fez-se com recurso ao software de apoio à análise de dados qualitativos webQDA.

O artigo está estruturado em quatro partes. Na seção 1 é apresentada a introdução à temática, enquanto na seção 2 é feita uma conceptualização do conceito de turismo rural. A identificação e caracterização dos diplomas legais que estiveram (e estão) por detrás da construção do turismo rural em Portugal, assim como, alguns comentários em torno destes diplomas serão apresentados na seção 3. Finalmente, à luz desta legislação e comentários, na seção 4 são apresentadas algumas notas conclusivas e considerações finais.

\section{Turismo Rural: um conceito multifacetado}

Embora com diferentes tradições e manifestações, o turismo no espaço rural não é uma atividade nova em Portugal ou em muitos países da União Europeia (KASTENHOLZ, 2013), podendo aliás, ser observado e interpretado de maneiras diferentes. O conceito ("turismo no espaço rural"), utilizado para designar o turismo praticado em áreas rurais, tem um sentido extremamente amplo e ambíguo, não permitindo circunscrever os seus limites nem definir o seu conteúdo com clareza. A realidade que pretende abarcar surge sob as mais diversas designações, muitas vezes com conteúdos diferentes - agroturismo, turismo verde, ecoturismo, enoturismo, turismo de natureza, entre outras (CAVACO, 1995; CUNHA, 2006).

De facto, na expressão "turismo no espaço rural" cabem uma série de situações e modalidades 
de turismo que podem ter na base da procura motivações frequentemente muito diferentes natureza, regresso ao passado, descanso, desporto e aventura, saúde, gastronomia, entre outras.

Por esta razão é útil precisar o sentido que se lhe atribui e delimitar o seu conteúdo. Assim, a primeira ideia que talvez nos surge a todos, é que, o turismo rural é o turismo praticado no campo, isto é em zonas rurais. A própria Organização para a Cooperação e Desenvolvimento Económico (OECD, 1994) define o turismo rural como qualquer tipo de turismo praticado em áreas rurais. Esta ideia esbarra, no entanto, em alguns entraves. Desde logo não é fácil definir as zonas rurais, apresentando elas próprias contornos muito distintos (OECD, 2006). Muitas delas encontram-se aliás num processo de transformação, o que, não permite a separação clara do meio urbano (CUNHA, 2006). Por outro lado, nem todo o turismo praticado em áreas rurais é estritamente rural - pode ter características urbanas e estar simplesmente localizado em áreas rurais (LANE, 1994). Algumas ofertas turísticas das áreas rurais (e.g. hotéis, complexos turísticos e aldeamentos turísticos) são, com efeito, deste tipo. Conforme Cavaco (1995), nestes casos, corre-se o risco de se subverter o significado de turismo rural como vetor de desenvolvimento rural.

Na sequência do referido acima, concordo com Lane (1994) que refere que o turismo rural na sua forma mais pura, para além de estar localizado em áreas rurais e de poder englobar ele próprio vários tipos de turismo, deve ser funcionalmente rural $^{2}$; permitir a participação nas atividades, tradições e estilos de vida da comunidade rural; ser tradicional em carácter e com ligação às famílias locais e ser rural em escala, e portanto, de pequena dimensão.

Uma das definições que melhor se aproxima das características referidas, diz respeito à que é proposta pela Federação Europeia de Turismo Rural - EuroGites. A federação define turismo rural como a atividade sustentável e multifuncional que está relacionada com os recursos locais - agricultura tradicional, cultura, ou valores naturais em zonas abertas ou pequenas populações onde a atividade turística não é a principal fonte de receitas (EUROGITES, 2015). Por seu turno as unidades de alojamento rurais devem proporcionar um serviço de pequena escala, onde se combinam uma atenção personalizada, zona calma, e padrões de qualidade ${ }^{3}$ e

\footnotetext{
${ }^{2}$ Isto é, construído de acordo com as características particulares do mundo rural e de empresas de pequena dimensão, de espaço aberto, de contacto com a natureza, incluindo o património, as sociedades e práticas tradicionais.

${ }^{3}$ Em consonância com a boa conservação do ambiente, autenticidade humana e cultural.
} 
estabelecer ligação com a comunidade local e as suas tradições, produtos, gastronomia e património, de acordo com os limites de segurança e sustentabilidade dos recursos (EUROGITES, 2015).

A nível nacional, as própria legislação prevê que o turismo rural na figura do TER seja definido como o "conjunto de atividades, serviços de alojamento e animação a turistas, em empreendimentos de natureza familiar, realizados e prestados mediante remuneração, em zonas rurais" [Dec-Lei (DL) n..$^{\circ}$ 54/2002 de 11 de Março]. É preciso, no entanto não esquecer que o turismo rural engloba muito mais que o alojamento em áreas rurais. Numa época em que o turista não se desloca simplesmente para dormir ou descansar, conceber o turismo rural baseado essencialmente no alojamento é cada vez mais limitativo.

\section{A Construção e Desenvolvimento do Turismo Rural em Portugal}

\subsection{As primeiras leis e a instituição legal do turismo rural em Portugal}

Desde cedo que o papel do setor público tem sido preponderante na difusão do turismo rural em Portugal. As primeiras leis oficiais acerca do turismo rural remontam aos finais dos anos setenta. A pretexto da recuperação e adaptação de solares de algumas regiões do país (Minho e Alentejo) incentivaram-se os proprietários de tais imóveis a disponibilizá-los para alojamento turístico em troca de um apoio financeiro (RIBEIRO, 2003). Em resposta a esta iniciativa foram lançados no mercado turístico no final da década referida, quartos em moradias particulares, sob a designação de turismo de habitação (TH) - DL n. ${ }^{0}$ 14/78 de 12 maio - um produto novo com vista a ampliar a capacidade de alojamento onde não existiam estabelecimentos hoteleiros ou estes eram insuficientes (RIBEIRO, 2003). A expressão "turismo de habitação" ganhou novo impulso passados apenas cinco anos através da possibilidade de atribuição de utilidade turística às respetivas casas (DL n. ${ }^{\circ}$ 423/83 de 5 de dezembro).

Um ano depois, são publicadas as normas de acesso a esta modalidade. De acordo com a nova

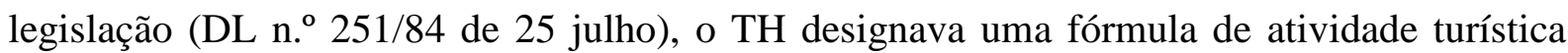
ainda experimental no país e que compreendia como elemento essencial a exploração de interesse turístico de uma casa de habitação pelo proprietário ou seu representante. Citando a mesma legislação, na altura "pareceu também razoável dar-se prioridade à recuperação de 
casas antigas e de reconhecido valor arquitetónico..." De acordo com a legislação supracitada o TH podia ser desenvolvido em dois tipos de casas, especificamente:

- edificação do tipo solar, casa apalaçada ou moradia unifamiliar, com valor arquitetónico, amplas dimensões, mobiliário e decoração de qualidade e instalações sanitárias condizentes (tipo A);

- edificação localizada em meio rural de natureza rústica ou de características regionais evidentes e com mobiliário e decoração adequados (tipo B).

A preocupação na defesa do património de valor arquitetónico é, de resto, integralmente partilhada e acolhida pelos promotores da primeira associação do setor de turismo rural em Portugal, a TURIHAB. Com efeito, num texto desta associação (TURIHAB, 2015), pode lerse que a associação tem como "principal objetivo fomentar a preservação dos magníficos Solares da região, bem como a sua tradição e cultura".

O ano da entrada de Portugal na então chamada Comunidade Económica Europeia (CEE), em 1986, assinala um marco histórico do TER em Portugal, não só pela instituição legal do produto turístico no âmbito do Plano Nacional do Turismo (PNT), mas também pela possibilidade de ajudas financeiras, muitas delas a fundo perdido que a organização internacional possibilitava (RIBEIRO, 2003). O produto turístico foi então definido como " $a$ atividade de interesse para o turismo, com natureza familiar, que consiste na prestação de hospedagem em casas que sirvam simultaneamente de residência aos seus donos" ou representantes (DL n. ${ }^{\circ}$ 256/86 de 27 agosto), podendo revestir a forma de $\mathrm{TH}$, Turismo rural (TR) ou Agroturismo (AG) (cf. quadro 1).

Quadro 1 - As modalidades de TER na década de 80

\begin{tabular}{l|l}
\hline TER & Descrição \\
\hline Turismo de Habitação & $\begin{array}{l}\text { Aproveitamento para o turismo de casas antigas, solares, casas apalaçadas ou de } \\
\text { residências de reconhecido valor arquitetónico, com dimensões adequadas, mobiliário } \\
\text { e decoração de qualidade. }\end{array}$ \\
\hline Turismo Rural & $\begin{array}{l}\text { Exercício da atividade turística em casas rústicas, com características próprias do meio } \\
\text { rural em que se insere. }\end{array}$ \\
\hline Agroturismo & $\begin{array}{l}\text { Exercício da atividade turística em casas de habitação ou seus complementos } \\
\text { integrados numa exploração agrícola, caracterizando-se por algum modo de } \\
\text { participação dos turistas nos trabalhos da própria exploração ou de formas de animação } \\
\text { complementares. }\end{array}$ \\
\hline
\end{tabular}


O espaço rural foi assim consagrado como espaço de turismo, de um turismo que sendo novo, se materializa como um produto sustentável e familiar e por essa via distinto dos que preenchiam o mercado. Tendo (provavelmente) em conta aquilo que vinha a ser feito na Europa, em Portugal foi também pela primeira vez enfatizado o turismo baseado na exploração agrícola - na forma de AG. É de referir aliás que, a própria CEE se comprometia a tomar em consideração para efeitos de financiamento os projetos de AG que lhe fossem apresentados pelos estados membros (CEE, 1988). Apesar da natureza familiar do produto turístico e da "tentativa de aproximação" à agricultura, vale a pena sublinhar que, dado que o TER impunha elevados padrões de qualidade dos edifícios e do seu recheio (JOAQUIM, 1999), inviabiliza o acesso à atividade por parte da maioria das famílias rurais portuguesas. Com efeito, a difusão do TER começava no topo da pirâmide social e estava longe de abranger aqueles que mais precisam - os pequenos e médios agricultores. Tendo como base este cenário, parece plausível afirma-se que, a grande preocupação (das entidades governamentais) na altura da criação do TER prendia-se com a diversificação da oferta do turismo nacional e com a preservação do património de valor arquitetónico das áreas rurais, e não tanto, com as questões relativas ao desenvolvimento rural (PATO, 2012).

\subsection{A segunda fase de desenvolvimento do turismo rural: a ênfase e perda das questões de desenvolvimento rural}

Decorreram aliás mais de dez anos até as preocupações com o desenvolvimento rural serem assumidas como um dos objetivos a atribuir ao TER. De facto a legislação posterior enfatizou a necessidade de revitalizar o tecido económico rural, contribuindo deste modo para o aumento da oferta de emprego e de rendimento das populações rurais e como tal para a diminuição do êxodo rural (DL n. ${ }^{\circ} 169 / 97$ de 4 de julho). O TER passou a ser definido como “o conjunto de atividades e serviços realizados e prestados mediante remuneração das zonas rurais, segundo diversas modalidades de hospedem, de atividades e serviços complementares de animação e diversão turística, tendo em vista a oferta de um produto completo e diversificado no espaço rural", prevendo-se também que, na perspetiva de incentivar o contacto entre populações e turistas, as unidades tivessem natureza familiar (DL n. ${ }^{\circ}$ 169/97 de 4 de julho). Pela leitura desta legislação, observa-se que é não só enfatizada a vertente do alojamento a turistas, como também se abre as portas à vertente da animação e diversão 
turística, especificamente aquela que é típica das áreas rurais, nomeadamente o património natural, paisagístico e cultural, os itinerários temáticos, a gastronomia, o artesanato o folclore, a caça, a pesca, os jogos e os transportes tradicionais. Não será certamente alheio a este facto, a perceção de que as necessidades dos turistas iam muito para além do simples alojamento e que, por si só, este não era suficiente para reter os turistas nas áreas rurais. Prova disso era (e continua aliás a ser) a curta permanência dos turistas nas unidades de TER (cf. IESE, 2008).

Conforme o quadro 2, as casas de TH, TR e AG mantêm no geral a sua filosofia, passando a partir deste ano a integrar o TER duas novas modalidades de casas menos exigentes em termos de construção, mobiliário e decoração: as casas de campo (CC) e o turismo de aldeia (TA). Particularmente, esta última modalidade que foi lançada em aldeias de montanha, tinha como intuito envolver as populações locais, criar emprego, recuperar o património, incentivar o artesanato e os produtos locais, melhorar a qualidade ambiental e por esta via combater a desertificação e o êxodo rural (CALHEIROS, 2012).

Quadro 2 - As modalidades de $\mathrm{TER}^{4}$ na década de noventa

\begin{tabular}{l|l}
\hline Casas de TER & Descrição \\
\hline \multirow{2}{*}{ Turismo de Habitação } & $\begin{array}{l}\text { Serviço de alojamento de natureza familiar prestado a turistas em casas antigas } \\
\text { particulares que, pelo seu valor arquitetónico, histórico ou artístico, sejam } \\
\text { representativas de uma determinada época, especificamente os solares e casas } \\
\text { apalaçadas. }\end{array}$ \\
\hline
\end{tabular}

Turismo Rural

Serviço de alojamento prestado a turistas em casas rústicas particulares utilizadas simultaneamente como habitação do proprietário, possuidor ou legítimo detentor e que, pela sua traça, materiais construtivos e outras caraterísticas, se integrem na arquitetura típica regional.

Serviço de alojamento prestado em casas particulares utilizadas simultaneamente como habitação do proprietário, possuidor ou legítimo detentor e integradas em explorações

Agroturismo agrícolas que permitam aos hóspedes o acompanhamento e conhecimento da atividade agrícola ou a participação nos trabalhos aí desenvolvidos, de acordo com as regras estabelecidas pelo responsável.

Casas de Campo Serviço de alojamento prestado por casas particulares e casas de abrigo situadas em zonas rurais, quer sejam ou não utilizadas como habitação própria dos seus proprietários, legítimos possuidores ou detentores.

Serviço de alojamento prestado num empreendimento composto por um conjunto de,

Turismo de Aldeia no mínimo, cinco casas particulares localizadas numa aldeia e exploradas de forma integrada, quer sejam ou não utilizadas como habitação do seu proprietário.

Fonte: DL n. ${ }^{\circ}$ 169/97 de 4 de Julho

\footnotetext{
${ }^{4}$ Para além destas modalidades a referida legislação considera ainda como empreendimentos de TER os hotéis rurais (HR) e os parques de campismo rural (PCR).
} 
Este novo quadro legislativo que abriu a possibilidade a um turismo menos elitista, com a introdução das modalidades de CC e TA, poderia vir a permitir um maior enraizamento da atividade turística a nível rural, podendo contribuir, de modo mais proveitoso, para a sustentabilidade económica das regiões e áreas envolvidas (Joaquim, 1999). Tendo, todavia, em consideração a nula representatividade do TA e a modéstia das CC poucos anos depois da sua criação, sou levada a crer, tal como refere Ribeiro (2003) que a extensão do TER a estas duas novas modalidades, digamos assim, mais populares, terá tido a ver com pressões político-legais (como poderia eventualmente ter sido o caso das associações de desenvolvimento local envolvidas na implementação do programa LEADER), do que com uma preocupação autêntica do legislador em diversificar a oferta do turismo rural.

A legislação subsequente integrou como empreendimentos de TER todas as formas de alojamento até aqui referidas, mantendo-se igualmente a filosofia de funcionamento das mesmas. O TER passou a ser definido como "o conjunto de atividades, serviços de alojamento e animação a turistas, em empreendimentos de natureza familiar, realizados $e$ prestados mediante remuneração, em zonas rurais" e os empreendimentos de TER os "estabelecimentos que se destinam a prestar serviços temporários de hospedagem e de animação a turistas em zonas rurais, dispondo para o seu funcionamento de um adequado conjunto de instalações, estruturas, equipamentos e serviços complementares, tendo em vista a oferta de um produto turístico completo e diversificado no espaço rural" (DL n. ${ }^{\circ}$ 54/2002 de 11 de março).

Apesar da importância que o turismo poderia vir a assumir na revitalização das áreas rurais, estranha-se que, as questões relativas ao desenvolvimento rural não tenham sequer sido referidas nesta nova legislação. Mais uma vez a tónica dominante pareceu ser a necessidade de preservar e valorizar o património das regiões rurais.

\subsection{As alterações mais recentes do desenvolvimento do turismo rural: a tónica do produto completo e diversificado em espaço rural}

A alteração mais recente da legislação do TER deu-se há pouco mais de sete anos em virtude das medidas do programa de Simplificação Administrativa e Legislativa (SIMPLEX). Em relação à anterior, a legislação agora apresentada mantém inalterada a conceção dos empreendimentos de TER, assim como das condições para o seu funcionamento, isto é, "os empreendimentos de TER 
são estabelecimentos que se destinam a prestar, em espaços rurais, serviços de alojamento a turistas, dispondo para o seu funcionamento de um adequado conjunto de instalações, estruturas e serviços complementares, tendo em vista a oferta de um produto completo e diversificado em espaço rural (DL nº 39/2008 de 7 de março). A grande preocupação do legislador parece, mais uma vez, centrar-se na necessidade de proporcionar um produto turístico completo $e$ diversificado. De facto, uma análise detalhada desta legislação deixa transparecer que as questões relativas ao desenvolvimento rural, não são nem sequer referidas.

Se o TH esteve na base da conceção do TER, a grande alteração desta legislação em relação às anteriores diz respeito à reformulação dos empreendimentos de TER. Assim, os empreendimentos de TER são separados dos empreendimentos de TH, deixando então esta última modalidade de fazer parte do TER. Conforme consta no quadro 3, o

TER passa a incluir simplesmente três modalidades: CC, AG e HR, sendo que o TH poderá ser desenvolvido não só em áreas rurais como urbanas.

Quadro 3 - Empreendimentos de TER e TH consagrados na atual legislação

\begin{tabular}{l|l}
\hline TER & Descrição \\
\hline Casas de campo & $\begin{array}{l}\text { Empreendimentos situados em aldeias e espaços rurais e se integrem pela sua traça, } \\
\text { materiais de construção e demais características, na arquitetura regional. } \\
\text { Quando as casas de campo se situarem numa aldeia e forem exploradas de forma } \\
\text { integrada por uma única entidade, podem usar a designação de turismo de aldeia. }\end{array}$ \\
\hline Agroturismo & $\begin{array}{l}\text { Empreendimentos situados em explorações agrícolas que permitam aos hóspedes o } \\
\text { acompanhamento e conhecimento da atividade agrícola, ou a participação nos trabalhos } \\
\text { aí desenvolvidos, de acordo com as regras estabelecidas pelo seu proprietário. }\end{array}$ \\
\hline THotéis rurais & $\begin{array}{l}\text { Estabelecimentos hoteleiros situados em espaços rurais que, pela sua traça arquitetónica } \\
\text { e materiais de construção, respeitem as características dominantes das regiões em que se } \\
\text { inserem. }\end{array}$ \\
\hline & $\begin{array}{l}\text { Estabelecimentos de natureza familiar instalados em imóveis antigos particulares que, } \\
\text { pelo seu valor arquitetónico, histórico ou artístico, sejam representativos de uma } \\
\text { determinada época, especificamente palácios e solares, podendo localizar -se em } \\
\text { espaços rurais ou urbanos. }\end{array}$ \\
\hline
\end{tabular}

Fonte: DL n. ${ }^{\text {o } 39 / 2008 ~ d e ~} 7$ de março

Uma nota que ressalta da análise da legislação, diz respeito ao facto de apenas ser mencionada a exigência do caracter familiar nos empreendimentos de TH. Em relação aos empreendimentos de TER, especificamente no caso do AG, a coabitação entre o dono do 
empreendimento (ou seu representante) e os turistas deixa de ser obrigatório. A alteração neste ponto e bem assim uma maior flexibilização do funcionamento do TER, deixa no entanto, em meu entender, cair (pelo menos parcialmente) uma das características e marcas indubitáveis do TER - o seu carácter mais familiar e personalizado.

\section{Notas conclusivas}

As orientações oficialmente traçadas a propósito do turismo rural em Portugal promoveram sem dúvida como protagonistas dessa oferta, indivíduos e famílias social e economicamente favorecidas, dispondo, comummente de um património edificado que escapa à larga maioria das famílias rurais em Portugal. Na prática, vários estudos (e.g. RIBEIRO \& MARQUES, 2002; RIBEIRO, 2003; SILVA, 2006; PATO, 2012) evidenciam que, no geral, os promotores dessa oferta pertencem a classes sociais médias a média-altas, não tendo aliás na maioria das vezes como atividade económica principal a atividade agrícola. Como refere Ribeiro (2003) esses promotores dispõe de outras fontes de rendimento para além da eventualmente gerada pela atividade turística, não dependendo ou sequer necessitando das receitas que a atividade turística pode gerar. Aliás, grande parte dos promotores terá aderido ao turismo rural por questões relativas à recuperação e preservação do património edificado, motivada pela disponibilidade de fundos financeiros e não por questões empresariais e/ou relativas ao desenvolvimento rural (PATO, 2012).

Com efeito, a legislação analisada ao longo deste ensaio, só parcialmente deu relevo às questões relativas ao desenvolvimento rural (especificamente na década de 90 mediante o DL n. ${ }^{\circ}$ 169/97 de 4 de Julho). De facto, sou levada a crer pela análise das sucessivas políticas, que para a administração central pareceu ser mais importante a oferta de um produto completo e diversificado em espaço rural, servindo então para tal, o património edificado e natural, o ambiente rural, a animação turística rural, a gastronomia típica, as tradições culturais do mundo rural, e outros demais recursos (só) passíveis de encontrar em espaço rural.

Mas mesmo assim, e não obstantes estes esforços das políticas públicas, a realidade mostra "uma coisa diferente". Com efeito, conforme referido por Pato (2012) a oferta do TER continua a basear-se essencialmente no alojamento turístico, sendo escassas as atividades de animação turística, sobretudo aquelas que são enfatizadas pela legislação e que são típicas da cultura popular - os itinerários temáticos, a gastronomia, o artesanato, o folclore, os jogos e os 
transportes tradicionais, citando só alguns exemplos. Adicionalmente não existe articulação entre as várias atividades que compõe o produto turístico (IESE, 2008) e tão pouco existe articulação com a população local (Pato, 2012), continuando a atividade turística a funcionar em "sistema fechado", o que naturalmente coloca em causa os eventuais benefícios do TER.

Outra nota que ressalta da análise da legislação respeitante ao TER diz respeito à aparente perda de familiaridade proporcionada pelas unidades turísticas. Com efeito, se durante mais de vinte anos (1997-2008) a legislação sublinhou o carácter familiar das unidades, o que no caso específico do TH, TR e AG obrigava à coabitação entre donos ou seus representantes e turistas, a legislação mais recente apenas menciona a questão no caso do TH, que curiosamente deixou de fazer parte do TER. O que me apraz perguntar nesta matéria é se o TER terá perdido parte da sua identidade?

As observações feitas ao longo deste texto não pretendem ser um manifesto contra o turismo rural, nem tão pouco contra a administração central do estado. Simplesmente são uma chamada de atenção no sentido de serem preconizadas políticas mais atentas e que preconizem a sociedade rural como um todo e não apenas algumas categorias da sociedade rural.

\section{Referências}

CALHEIROS, F. (2012). O leader e o turismo rural. Pessoas e Lugares, 6, 7.

CAVACO, C. (1995). Turismo Rural e Desenvolvimento local. In C. Cavaco (Ed.), As regiões de fronteira, Estudos para o desenvolvimento rural e Urbano (pp. 351-408). Lisboa: Centro de Estudos Geográficos da Universidade de Lisboa.

CEE (1988). The Future of Rural Society. Commission communication transmitted to the Council and to the European Parliament. COM (88) 501 final, 29 July 1988.

CUNHA, L. (2006). Economia e Política do Turismo. Lisboa: Editoral Verbo.

EUROGITES. (2015). Public Documentation. Acedido a 13 abril, de http://www.eurogites.org/documents/

IESE. (2008). Estudo de caracterização do Turismo no Espaço Rural e do Turismo de Natureza em Portugal. Lisboa: DGADR.

JOAQUIM, G. (1999). Turismo e mundo rural: que sustentabilidade? In C. Cavaco (Ed.), Desenvolvimento Rural Desafio e Utopia (pp. 305-312). Lisboa: Centro de Estudos Geográficos da Universidade de Lisboa.

KASTENHOLZ, E. (2013). Creating, sharing and living rural tourism experiences:insight from a research project in Portugal. Paper presented at the International Conference on Rural Tourism - Reinventing rural tourism and the rural tourism experience, Aveiro. 
LANE, B. (1994). What is rural tourism? Journal of Sustainable Tourism, 2(1\&2), 7-21.

OECD (1994). Tourism strategies and rural development. Paris: Organization for Economic CoOperation and Development.

OECD (2006). The new rural paradigm policies and governance. Paris: OECD.

PATO, L. (2012). Dinâmicas do turismo rural - impactos em termos de desenvolvimento rural. $\mathrm{PhD}$ thesis, Universidade de Aveiro, Aveiro.

RIBEIRO, M. (2003). Espaços rurais como espaços turísticos. In J. Portela \& J. C. Caldas (Eds.), Portugal Chão (pp. 199-215). Oeiras: Celta Editora.

RIBEIRO, M. \& MARQUES, C. (2002). Rural Tourism and the Development of Less Favoured Areas - between Rhetoric and Practise. International Journal of Tourism Research, 4(3), 211-220.

SILVA, L. (2006). O Turismo em Espaço Rural: Um Estudo da Oferta dos Promotores. CIES eWorking Paper $n^{\circ}$ 16. http://www.cies.iscte.pt/destaques/documents/CIES-WP16 Silva .pdf

TURIHAB. (2015). Perfil da TURIHAB - Associação de Turismo de Habitação. Acedido, 17/2/2011, de http://www.solaresdeportugal.pt/PT/perfil.php

URRY, J. (2002). The Tourist Gaze. London: SAGE Publications.

\section{Legislação}

DL n. ${ }^{0} 14 / 78$ de 12 maio

DL n. ${ }^{\circ} 423 / 83$, de 5 de dezembro

DL n. ${ }^{\circ} 251 / 84$, de 25 julho

DL n. ${ }^{\circ} 256 / 86$, de 27 agosto

DL n. ${ }^{\circ}$ 169/97 de 4 de julho

DL n. ${ }^{\circ} 54 / 2002$ de 11 de março

DL n. ${ }^{\circ} 39 / 2008$ de 7 de março

\section{Recebido em: $20 / 04 / 2015$ ( $1^{\text {a }}$ versão) $09 / 11 / 2015$ ( $2^{\text {a }}$ versão $)$}

\section{Aprovado em: 14/12/2015}

